\title{
A psychedelic education: How an initial encounter with LSD changed my mind and shaped my life and career*
}

\author{
RONALD LEE ZIGLER** \\ Social Science Division, Penn State Abington, Abington, PA, USA
}

(Received: January 21, 2019; accepted: February 11, 2019)

\begin{abstract}
In a letter to Humphrey Osmond in 1953, Aldous Huxley speculated about a "new system" of education in which psychedelics may play a part "by making it possible for young people to 'taste and see' what they have learned about at second hand, or directly but at a lower level of intensity, in the writings of the religious, or the works of poets, painters and musicians." In 1968, the author unwittingly engaged himself in this "new system" of education. This essay details the events that led to his initial experience with LSD as well as how that initial encounter proved to be a seminal experience in his life, changed his mind, and shaped his career path.
\end{abstract}

Keywords: education, visionary experiences, spiritual, religion, LSD

\section{INTRODUCTION}

At the time of renewed awareness and, possibly, acceptance of the application of psychedelics in our culture, I have been provided an incentive for revisiting my own psychedelic experiences. For over 50 years, I have periodically reflected on my experiences with LSD since they were so transformative. The decision to write an account of my most powerful psychedelic encounters emerged in 2001, shortly after my mother's death. The demise of a parent or close friend often inspires reflection on one's own mortality. But for me, it meant once again reflecting on those life-changing experiences that not only changed my mind, but also shaped the trajectory of my life and my career.

Now at the age of 70 years, I find myself at the end of my career if not my life as well (although the light at the end of that tunnel is at least metaphorically looming closer as well). Furthermore, in the wake of Michael Pollan's excellent book on psychedelics, "How to Change Your Mind" (Pollan, 2018), I felt these events made this a propitious time to tell a story that has been unspoken, but nonetheless implicit during my entire career.

For the past 22 years, I have been a faculty member at Penn State Abington, a college campus of Penn State outside of Philadelphia. I have spent over 30 years in education, both as a secondary social studies teacher as well as a college professor. While I managed to successfully negotiate the challenge of publishing, rather than perishing, I have never written about those very personal experiences that shaped what I have been writing about professionally. The reasons are, perhaps, obvious. Candid discussions of one's personal experiences with psychedelics are somewhat more controversial for individuals like myself who are devoted to the challenges of public education - especially if one is going to suggest, as I am compelled to do now, that these experiences where among the most powerfully educational experiences of my life. In this respect, I am only applying a basic tenet of the educational philosopher John Dewey. Namely, that at its most basic level, education is all about the process of "forming fundamental dispositions, intellectual and emotional, toward nature and fellow-men" (Dewey, 1944, p. 383). By that account, my psychedelic experiences were highly educational insofar as they shaped these fundamental dispositions within me.

That such experiences may be deemed an important part of both education and the maturation process - not surprisingly - advanced earlier by Aldous Huxley. Huxley, of course, is among other things well known for his 1954 essay "The Doors of Perception" where he describes his own experience with mescaline. However, Huxley also addressed the educational value and application of psychedelics in his somewhat neglected but highly important 1962 novel "Island" - a story aptly described by author Alan Watts as a "thinly fictionalized collection of essays on education, psychology and metaphysics" (Watts, 1964, pp. 292-294). Among the traditions portrayed in the society depicted in this novel is a rite of passage for young people. Huxley's imaginary rite of passage would begin with a highly demanding rock-climbing ordeal after which the

\footnotetext{
*RLZ is the author of The Educational Prophecies of Aldous Huxley: The Visionary Legacy of Brave New World, Ape and Essence and Island (Routledge International Studies in the Philosophy of Education), 2015. This current essay has been adapted from his latest book, My Psychedelic Education: A Chronicle of LSD Induced Visionary Experiences that Changed My Mind, July 31, 1968 through January 1969 (independently published on Amazon), 2018. This is available in paperback or on Kindle. ** Corresponding address: Assoc. Prof. Ronald Lee Zigler; Social Science Division, Penn State Abington, Abington, PA 19001, USA; Phone: +1 215881 7335; Fax: +1 215881 7825; E-mail: rlz2@psu.edu
}

This is an open-access article distributed under the terms of the Creative Commons Attribution-NonCommercial 4.0 International License, which permits unrestricted use, distribution, and reproduction in any medium for non-commercial purposes, provided the original author and source are credited, a link to the CC License is provided, and changes - if any - are indicated. 
adolescents would all enter a temple for a ceremony where they are given "four hundred milligrams of revelation" (Huxley, 1962a, pp. 195-196). The purpose of this experience is to provide, along with the rock-climbing, "Two firsthand experiences of reality, from which any reasonably intelligent boy or girl can derive a very good idea of what's what" (Huxley, 1962a, pp. 195-196). However, unlike the adolescent rite of passage portrayed in Huxley's novel, the conditions under which my own psychedelic revelations transpired were, unfortunately, far from ideal if not downright problematic. Nonetheless, they were educational in the fullest sense of that word.

As indicated, I have spent my career avoiding a candid discussion of these formative experiences that I underwent between the summer of 1968 through the winter of 1969 . Instead of engaging in such a discussion, I have advanced my professional career as a scholar writing about the topics, challenges, and issues that these formative experiences inspired. Thus, my record of over 30 professional publications has discussed consciousness, morality, and human values, rarely using the term "spiritual." Only my 2015 book on Aldous Huxley allowed me to more fully examine many of the topics and issues, which have preoccupied me for over 40 years (Zigler, 2015). Indeed, reading between the lines, the book is practically autobiographical. The only missing element is what I would like to provide now. An explicit discussion of those psychedelic experiences, which have remained an indelible if seldom, discussed part of who I am.

Following is a chronical of my first experience with LSD as well as the interpretation it inspired. Among approximately 20 trips on LSD, only 5 of them were truly extraordinary, including my first encounter. They collectively constitute my psychedelic education. This essay then is an account of my initial launch and the trajectory that has set for me, not only for my subsequent experiences, but also for my life and career as well.

\section{UNBOUNDEDNESS IN A CUP OF TEA}

It was during my second year of college - in the spring of 1968 - that I first encountered drug experimentation among friends. I was 19 years old. Curiously, I had no interest in the marijuana with which my best friend Michael was experimenting. To me, it was just "dope" and I let Michael know that this is what the effect of smoking marijuana was having on him: making him a dope. He did not appreciate my comments and my lack of sympathy for recreational marijuana use. This created a serious strain in our friendship. Even when he finally forced me to try it, I was unimpressed. It simply did not seem to have much of an effect on me.

However, later that summer LSD arrived in town, perhaps not for the first time, but probably the first time it was widely available among the youth culture surrounding the University of Cincinnati where I was enrolled as an undergraduate. I can still recall the auspicious evening of July 31, 1968. A number of friends and acquaintances were already on trips and I found myself absorbed in a discussion with a person named Conly: a principal dealer and distributor of LSD that summer. LSD, of course, is not an addictive drug so what its advocates "pushed" was "mind expansion" and "consciousness raising." I recall initially resisting what Conly was advocating. Nevertheless, when confronted with the possibility of a "trip" on LSD, I reconsidered. In no small measure, I did this because of a remark made by my highschool zoology teacher who made a lasting impression on me. He was the first person I heard to suggest that the average individual uses only $10 \%$ or $15 \%$ of his or her full mental potential. The possibility of expanding that potential had inspired me and while marijuana did not appear to advance this goal, I had then become familiar with the claim that LSD represented a means of expanding human consciousness. I remember thinking that since I deemed myself a reasonably straight, levelheaded, rational individual, I was going to cross that threshold, which LSD represented and not get totally "lost" and lose direction - at least this was my mission. Rather, I would "return" from my "trip" so that I could understand both sides of the controversies that surrounded the drug at that time. Clearly, and ultimately, I could not resist the possibility of exploring that largely untapped human potential, which had begun to interest me since high school, in a most direct and immediate way.

There was a mix of fear, caution, and excitement in me at that time. Excitement, naturally, accompanies any pioneering endeavor, and I did subsequently very much feel like a pioneer, even if I was one among many. I remember quite clearly that fateful moment during which Conly and I were debating. We were in the little kitchen of the apartment of a friend named Stuart when I paused from our discussion. Finally, I stated, "If you put a capsule of LSD on the table right now I'll take it." He did this, and I unhesitatingly picked it up and swallowed it. It is as if we played out a precursor to the well-known scene in the 1999 movie "The Matrix." In that scene, the actor Keanu Reeves' character "Neo" is presented a choice between swallowing a red capsule or a blue capsule. Only, in my experience, the choice was between taking one capsule (it happened to be white) or walking away from the table. Truly, like Neo, after swallowing the capsule, I have not been the same since.

We still do not fully understand LSD regarding its impact on us and the changes it may bring about, although current research has begun to shed light on its effect on our brains. One interesting finding from contemporary neuroscience is the discovery that psychedelic drugs, like LSD and psilocybin, act on the brain's neurotransmitter serotonin as a receptor agonist (Meyer \& Quenzer, 2005, pp. 348-356). As such, it is unlike the effect of amphetamines, cocaine, ecstasy, or opiates and thus it has never been found to be addictive or otherwise damaging to the human nervous system. Furthermore, studies involving various brain-imaging technologies have indicated that these drugs alter neural functioning in what neuroscientists refer to as the medial default mode network of the brain (Barrett \& Griffiths, 2017, p. 474). Decreased blood flow in these parts of the brain during LSD or psilocybin experiences correlates with increased intensity of the drug effect and a decreased sense of self - specifically, promoting the sense of selftranscendence or ego-dissolution during a psychedelic session. Most significantly, similar activity and connectivity in these brain regions are also altered by acute and long-term meditation practices.

Whatever the precise impact may be, psychedelics like LSD, psilocybin, and mescaline must be understood for both 
the generic features of the experiences they nearly produce in everyone, as well as for the unique impact that they are likely to have on any given individual mind. I have subsequently discovered that unlike many individuals who dismissed much of their experience as simply "drug-induced" hallucinations that lacked any substantial reality, I had an entirely different response to my experiences. From the very beginning, I was struck with what seemed to me to be the very natural images and sensations with which I was confronted. That is, I had a deep sense that what I was experiencing was always present, beneath a veil or fog that obscured my vision. LSD, as it were, somehow simply brought to my awareness something that was always present, but to which I was not fully attending. LSD researcher Stanislav Grof has underscored this same idea - he maintains LSD amplifies what is already present in the mind (Grof, 1975).

Among the remarkable episodes during my first LSD session was my curious fascination with blank paper. I recall asking for a piece of paper so that I could write or draw; however, I became lost staring at the blank pages. In retrospect, I have come to see my focus on blank paper, as a fascination with what was going on inside my mind. Blank paper appears to provide a screen, as it were, on to which the mind projects itself. I found this alternately more interesting and compelling than the enhanced stimulation of the outside world (e.g., provided by music) that an LSD trip normally affords an individual. Eventually, this fascination with the inside world would lead me to close my eyes and look much more closely inside myself during subsequent LSD sessions. Closing the eyes during an LSD trip is a well-understood means of dramatically intensifying the nature of the LSD experience. Ultimately, the experiences I was to have with my eyes closed are those that led to my deep and abiding interest in and commitment to the practice of meditation.

All LSD sessions have a "peak" or most intense moment, and the peak of my first experience is still a vivid memory. Until that instant, I had been alternately listening to music and looking at blank paper when I began to feel unsettled largely, on account of my approaching that most intense period of my first trip. I do not remember whether I requested, or was simply offered a cup of tea, but I recall sitting at the kitchen table at Stuart's apartment with a cup of fresh tea in front of me. It was very late - or early, since I had swallowed the white LSD capsule at about 11:00 p.m. and it was now a few hours later. As I looked at the cup of tea in front of me, I became aware of myself formulating the intention to pick up my teaspoon and reach across the table for the sugar bowl, so that I may put a couple of teaspoons full of sugar into my cup of tea. Yet, before I allowed myself to act upon this intention, a powerful and compelling thought began to grip my mind: I had the strange but compelling premonition that I did not really need to reach over for the teaspoon and sugar. Somehow, as strange as this must seem, it nonetheless appeared to me possible that if I only focused, concentrated, and applied myself with the requisite effort, I could actually move the teaspoon into the sugar bowl without lifting a finger and thereby direct the sugar into my tea. However, then, in an instant before I could even contemplate the process of mustering the requisite mental effort for this task, I quickly realized just as forcefully and dramatically that I did not really need the teaspoon at all! If I only applied myself, I could bring the sugar directly into my cup of tea! Once again, I did not have any time to mount such an effort for this endeavor either before yet another thought rushed into my mind: why do I need the sugar? I could simply think the tea sweet! Again, in the context of my experience, this seemed like a real possibility; the only question was a matter of directing my attention in such a manner as to achieve this desired outcome. Yet, once again, before I could test my intuitions and formulate the concerted effort to bring about the fulfillment of my desire, another thought gripped my mind: why do I even need the tea? I could simply "think" the fulfillment it was supposed to bring me. My mind's potential seemed so vast, unlimited, and unbounded that my attachment to sugar, sweetness, and tea all began to pale in comparison. Indeed, the course of my thinking reached a dramatic climax when I began to wonder why we really needed anything at all in the outside world to bring us happiness. It was becoming clear to me that the ultimate source of our happiness and fulfillment lay within us. Furthermore, I began to sense that the part of me with which I was traditionally identified - namely my body and physical presence - was but a pale, minor element to my identity, to my true self (or as I subsequently learned through my study of Indian Philosophy, my true Self). It was at this moment, as they say, that the trip became "heavy." As many others might also observe, I began to experience the dissolution of my individualized, highly localized ego. I do not recall if I ever drank that cup of tea, having become lost in the unboundedness of the moment.

For the first time in my life, I was truly confronting the question of what it means to be human and being an individualized, localized body did not seem to be a particularly prominent component of that identity. I thus entered a depressed phase of my first LSD trip (a not too uncommon phenomena) in which I felt baffled by the paradox, which has, perhaps not changed since - the inescapable discrepancy that exists between the human potential and the human condition. After reaching this peak, I began the gradual process of "coming down" from the trip and slowly returning to ordinary reality.

I arrived home that morning, having not gone to sleep. I was waiting until 11:00 a.m. when I would report to the swimming pool where I worked as a lifeguard. While sitting in my bedroom listening to music with headphones, my father burst into the room and announced that my cousin Dave had escaped from our local state mental institution (this was 1968, before deinstitutionalization of the mentally ill). My dad told me that Dave had appeared at our front door and then proceeded up the street in a hurry. Consequently, my dad and I got into my car and we tracked Dave down. I recall telling my dad to do the talking, but after picking up Dave, I found myself trying to calm Dave down, while my dad had been reprimanding him. We returned him to the Longview State Mental Hospital that was located only two miles from our home. When I related this story to friends - that I had visited a mental institution under such circumstances in the wake of my first LSD trip they were nearly incredulous. Coupled with the fact that I was not known as a marijuana user (or "pothead") before launching onto my first LSD trip, I subsequently gained a measure of notoriety among some members of the local psychedelic community. 


\section{EASTERN PHILOSOPHY: CLASSROOM AND LABORATORY FOR A PSYCHEDELIC EDUCATION}

It was during the fall semester of 1968 that I had begun a formal study of Indian Philosophy. I had enrolled in the three-part Asian Civilizations sequence of courses at the University of Cincinnati that included the study of Indian History, Philosophy, and Religion. I eagerly absorbed the required readings in philosophy and religion for the course, since they were highly compelling in light of my LSD experiences. Indeed, psychedelics appear to represent an appropriate "laboratory" experience that complements many of the texts of Eastern Philosophy. It is no coincidence that writers like Aldous Huxley had already examined the relevance of the mystical literature in general and Eastern Philosophy in particular to the psychedelic experience. However, until the fall of 1968, I had yet to read these works. On that account, a required course reading I studied that fall entitled "Sources of Indian Tradition," afforded me a framework of ideas with which I could interpret my psychedelic experiences. This particular volume was composed of a collection of works from Indian Philosophy and Religion. A statement from one reading in this text still resonates. It is from the commentary of Shankara on the Vedanta Sutras:

Ordinary people and the materialists are of the view that the Self is just the body qualified by intelligence; others think that it is the intelligent sense organs themselves that are the Self: still others, that it is the mind; some hold it as just the fleeting consciousness of the moment; some others as the void; certain other say that there is some entity, which is different from the body, etc., and which transmigrates, does and enjoys; some consider him as the enjoyer and not as the doer; some that there is, as different from the above entity, the Lord who is omniscient and omnipotent. According to still others, it is the inner Self of the enjoyer. Thus, resorting to reasonings and texts and the semblances thereof, there are many who hold divergent views. (de Bary, 1966, p. 284)

My discovery of a discussion that entertained these speculations was of great significance to me. They underscored the vitality and possible validation for an interpretation of my experiences that was becoming, perhaps, commonplace and difficult to ignore among those involved with psychedelics. I felt like I had a glimpse of the meaning of Self - as opposed to simply self - a larger, more expanded meaning to that term, which embraces a reality beyond our own skin, insulated ego identity, and ordinary experience. It is a notion more common to several Eastern Philosophical traditions. Hence, I felt that I had an insight into a dimension of our most intimate identity that transcended localized, individual human bodies, and betrays the fundamental unity of humanity and nature - indeed, an underlying unity to all of creation. Moreover, I read with complete fascination those passages of the Bhagavad Gita, which were also required reading in my course. This ancient text makes explicit and repeated references to the Self. Accordingly, the Bhagavad Gita maintains that when we are compelled to assess our fundamental identity, we confront a dimension of human awareness or consciousness that "is not born, nor dies," "nor having once come to be will ever again come not to be." Thus, regarding the true nature of the individual's identify, it is said, "He is unborn, eternal, permanent and primeval; he is not slain when the body is slain" (de Bary, 1966, p. 284).

The doctrine of transmigration of the soul - through many lifetimes - suddenly became worthy of serious consideration, and the Bhagavad Gita was explicit about this doctrine stating: "Just as a man, having cast off old garments, puts on other, new ones, even so does the embodied one, having cast off old bodies, takes on other, new ones." Slowly, the whole notion of spiritual development and corresponding spiritual disciplines became topics that I could not ignore. On this account, I began to expand my reading beyond what was required by my college class to include works by Swami Vivekananda and Paramahansa Yogananda - two men who helped introduce many of these ideas to the Western World in the first half of the 20th century. It was also at this time that I first read Huxley's account of his own experience with the psychedelic mescaline in "The Doors of Perception" (Huxley, 1954). Among the most memorable ideas I recall Huxley discussing in that text is the idea that the human brain functions more like a filter or "reducing-valve" that decreases our sensory input. It does this out of necessity so that we may negotiate our physical world of biological utility and survival against the onslaught of physical threats to our health and well-being. However, Huxley goes on to suggest that the function of spiritual exercises as well as psychedelics is to temporarily bypass this filter or reducing-valve and thereby dramatically enlarge our experience by expanding human consciousness. Implicit in these assumptions is the idea that the brain does not really produce consciousness; rather, it acts like a receiver, which transmits consciousness. My own experiences with LSD made this assertion quite credible.

Collectively, these various readings prompted me to view the individual mind as a garden that needed to be properly cultivated, less it become overwhelmed by "weeds" (misguided assumptions and actions) and its full potential for expanded consciousness undermined. Meditation, as a specific mental and spiritual discipline, began to make sense, whereas only months earlier, it seemed entirely foreign to me and likely to suspect. Nonetheless, one of the many ways in which LSD altered my fundamental dispositions was in the manner it made me more receptive to the value of meditation.

In September 1968, I attended a lecture on the Transcendental Meditation technique (TM). Unlike later years, this lecture by an older, gray-haired woman named Margaret Carroll was all about "God-realization" rather than health and stress reduction. However, talk about "God-realization" did not faze me, notwithstanding the fact that I had become an agnostic when I was 14 years old. In the wake of my initial LSD experiences, I had unwittingly become a student enrolled in a "new system" of education first conceived by Aldous Huxley in 1953. In a letter to researcher Humphrey Osmond, Huxley wrote of this new system of education. In that system, "mescaline or some other chemical substance may play a part by making it possible for young people to 'taste and see' what they have learned about at second 
hand, or directly but at a lower level of intensity, in the writings of the religious, or the works of poets, painters and musicians" (Huxley, 1953, p. 30). Indeed, I have little doubt that I benefited from my experiences with psychedelics, which allowed me to "taste and see" in a most vivid manner the kind of experiences that make religion and human spirituality truly meaningful rather than simply a stagnant, dogmatic ideology. On that account, Margaret Carroll's discussion of meditation in the context of religion and human spirituality made sense. Only 2 months earlier, I would have had an entirely different response - one that was much more skeptical.

It was not until March of 1969 that I finally learned TM - something I have continued to practice ever since. Regarding meditation, it is important to note that it constitutes an example of what Aldous Huxley referred to as a method of nonverbal education - part of what he also deemed the "nonverbal humanities" and thus an important part of his "new system" of education as well (Huxley, 1962b, p. 307).

There is little doubt in my mind that my commitment to a meditation discipline was in no small measure secured because of a series of LSD-induced visionary experiences that I underwent between November 1968 and January 1969. Until now, however, there has been something slightly disingenuous about my career since completing graduate school in 1977. During this period, I have largely, if not exclusively, confined my professional writings and conference presentations to explaining the legitimacy and importance of nurturing subjective experience through meditation. I did this largely in the context of addressing issues in the philosophy of moral education. In this manner, I merely wrote about the topics that my experiences with psychedelics inspired, rather than my actual psychedelic encounters themselves. In doing so, I have come to recognize a certain irony - namely, that it was not through such scholarly contributions that I myself came to my understandings and my meditation practice. Rather, it was a direct experience via psychedelics that allowed me to "taste and see" why such mental disciplines were important. Now as a tenured professor who is about to retire, I derive a measure of satisfaction in not only addressing this neglected matter, but also in finding that I am not alone in the academic world. The contributions of Kenneth Tupper as well as William Richards illustrate this and have thus begun what is likely to become an enthusiastic, important, and possibly contentious conversation.

Richards has argued convincingly that there are more subjects than merely the study of Eastern Philosophy that can be enhanced and illuminated by psychedelics - or entheogens, Huston Smith's preferred term (Smith, 2000). Rather, Richards advances an idea that I have also contemplated. Namely, that Plato's famous allegory of the cave are among those topics, which take on special meaning for those who have been transported, so to speak, "outside the cave" through a psychedelic vision (Richards, 2018, pp. 153-154). On that account, trying to advance a discussion on the development of human consciousness as an educational objective has often left me feeling like someone on the outside looking in - back into the cave (curiously, at many conferences, I have attended during my career, it was I who retreated to my room at the end of the day to meditate, rather than joining my colleagues at the cocktail lounge or bar).

Moreover, in the work of Kenneth Tupper, educators are now being provided an opportunity to contemplate a plausible claim that I was not willing to broach when I was in graduate school over 40 years ago. This is the explicit advancement of a conceptual framework for entheogenic education by viewing these substances as educational technologies. In doing this, Tupper acknowledges that he is taking advantage of the "renaissance of psychedelic studies," which have emerged in the 21 st century to advance his notion of entheogenic education - this is the same renaissance that inspired me to tell my story as well. Tupper summarizes the educational value of entheogens and psychedelics by "their capacity - when used respectfully and circumspectly - to reliably evoke experiences of wonder and awe, to stimulate transcendental or mystical experience, and to catalyze a sense of life meaning or purpose" (Tupper, 2014, p. 18). This is certainly not a claim I would contest.

What then remains for the advancement of entheogenic education is this: first, the scientific, medical, and political communities must forge a new, unambiguous consensus regarding the role of psychedelics in our culture. If these substances can be decriminalized, and made available for legal, therapeutic use, then the next step will be clear. Initially, there should emerge an entheogenic laboratory school that will much serve the same purpose as the progressive laboratory school created by John Dewey at the University of Chicago over 100 years ago. Whether as a private school, charter school, or university-affiliated institution, these entheogenic laboratory schools may then serve as real models of the "new system" of education envisioned by Aldous Huxley.

Acknowledgements: The author has no financial assistance to acknowledge. He received assistance for his book on Huxley but not for this project.

Conflict of interest: The author has no financial interests to disclose.

\section{REFERENCES}

Barrett, F. S., \& Griffiths, R. R. (2017). Classic hallucinogens and mystical experiences: Phenomenology and neural correlates. Current Topics in Behavioral Neuroscience, 36, 393-430. doi:10.1007/7854_2017_474

de Bary, W. T. (Ed.). (1966). Sources of Indian traditions. New York, NY: Columbia University Press.

Dewey, J. (1944). Democracy and education: An introduction to the philosophy of education. New York, NY: MacMillan.

Grof, S. (1975). Realms of the human unconscious: Observations from LSD research. New York, NY: Viking Press.

Huxley, A. (1953). Letter to Dr. Humphrey Osmond. In M. Horowitz \& C. Palmer (Eds.), Moksha: Huxley's classic writings on psychedelics and the visionary experience (1931-1963). Rochester, VT: Park Street Press. 
Huxley, A. (1954). The doors of perception and heaven and hell. New York, NY: Harper Perennial.

Huxley, A. (1962a). Island. New York, NY: Perennial Classics Edition.

Huxley, A. (1962b). Education on the nonverbal level. In R. S. Baker \& J. Sexton (Eds.), Complete essays: Volume VI, 1956-1963, and Supplement, 1920-1948 (pp. 303-317). Chicago, IL: Ivan R. Dee.

Meyer, J. S., \& Quenzer, L. F. (2005). Psychopharmacology: Drugs, the brain, and behavior. Sunderland, MA: Sinauer.

Pollan, M. (2018). How to change your mind: What the new science of psychedelics teaches us about consciousness, dying, addiction, depression and transcendence. New York, NY: Penguin Press.
Richards, W. (2018). Sacred knowledge: Psychedelics and religious experiences. New York, NY: Columbia University Press.

Smith, H. (2000). Cleansing the doors of perception. New York, NY: Tarcher/Putnam.

Tupper, K. (2014). Entheogenic education: Psychedelics as tools of wonder and awe. MAPS Bulletin Special Edition, Spring, 24(1), 14-19. Retrieved from https://maps.org/news-letters/ v24n1/v24n1_p14-19.pdf

Watts, A. (1964). Some remembrances of Aldous Huxley. In M. Horowitz \& C. Palmer (Eds.), Moksha: Aldous Huxley's classic writings on psychedelics and the visionary experience (1931-1963) (pp. 292-294). Rochester, VT: Park Street Press.

Zigler, R. L. (2015). The educational prophecies of Aldous Huxley: The visionary legacy of brave new world, ape and essence and island. New York, NY: Routledge. 